\title{
Dietary Exposure Assessment of Paralytic Shellfish Toxins through Shellfish Consumption in Shenzhen Population, China
}

\author{
Yan Zhou \\ Shenzhen Center for Disease Control and Prevention \\ Shenpan Li \\ Shenzhen Center for Disease Control and Prevention \\ Jianying Zhang \\ Shenzhen Custom \\ Jinzhou Zhang \\ Shenzhen Center for Disease Control and Prevention \\ Zhou Wang \\ Shenzhen Center for Disease Control and Prevention \\ Liubo Pan \\ Shenzhen Center for Disease Control and Prevention

\section{Baiqiang Huang} \\ Shenzhen Center for Disease Control and Prevention \\ Ke Huang \\ Shenzhen Custom

\section{Xiao Chen} \\ Shenzhen Center for Disease Control and Prevention

\section{Qionghui Zhao} \\ Shenzhen Custom

\section{Tianjiu Jiang} \\ Jinan University \\ Jianjun Liu( $\square$ junii8@126.com ) \\ Shenzhen Center for Disease Control and Prevention
}

\section{Research Article}

Keywords: Paralytic Shellfish toxins, Saxitoxin, dietary exposure assessment

Posted Date: July 6th, 2021

DOI: https://doi.org/10.21203/rs.3.rs-630710/v1

License: (c) (i) This work is licensed under a Creative Commons Attribution 4.0 International License. Read Full License 
Version of Record: A version of this preprint was published at Environmental Science and Pollution Research on September 13th, 2021. See the published version at https://doi.org/10.1007/s11356-021-16249-4. 


\section{Abstract}

Paralytic shellfish toxins (PSTs) produced by certain marine dinoflagellates accumulate in filter-feeding marine bivalves. We used LC-MS/MS to detect and quantify 13 PSTs in 188 shellfish samples of 14 species collected from Shenzhen city's Buji seafood wholesale market from March 2019 to February 2020. Twenty-six of 188 shellfish samples (13.8\%) were PST- positive, with highest values in samples of the Noble clam Chlamys nobilis (10/34, 29.4\%). Samples originating from Nan'ao island among 11 source sites in China recorded the highest detected rate (7/17, 41.2\%). Samples containing PSTs were concentrated in Spring and Winter, with the highest levels in March $>$ December > January. Among PSTs detected, C1 was dominant. Acute dietary exposure assessments for Shenzhen residents were based on $\mathrm{P}_{99}$ consumption data (139.2g/day) and maximum PST concentration for each shellfish species. The outcome for Chlamys nobilis was $2.4 \sim 3.7$-fold higher than recommended ARfDs (0.5 $0.7 \mu \mathrm{g} \mathrm{STX} \mathrm{eq./kg} \mathrm{bw/day).}$ Mean PST concentration (10.9 $134.1 \mu \mathrm{g}$ STX Eq. $/ \mathrm{kg}$ ), mean shellfish consumption ( $4.8 \mathrm{~g} / \mathrm{day})$ and $\mathrm{P}_{99}$ consumption data were used to assess chronic dietary exposure. The results were lower than the recommended ARfDs. In conclusion, residents in Shenzhen are at risk for acute PST poisoning, while relatively safe from chronic PST exposure.

\section{Introduction}

The escalating incidence of paralytic shellfish poisoning (PSP) is associated with increasing harmful algal blooms linked to global ocean warming and anthropogenic activity that promotes eutrophication (Visciano et al., 2016). Paralytic shellfish toxins (PSTs) are mainly produced by marine dinoflagellates, such as Alexandrium, Gymnodinium, and Gonuaulax spp, and accumulated in filter-feeding bivalves (Liu et al., 2004; Asakawa et al.,2006; Shin et al., 2018). Bivalves commonly contaminated with PSTs include saltwater clams (Meretrix lyrata, Siliqua patula, Paphi subtriangulata, Saxidomus giganteus), mussels (Perna viridis, Mytilus edulis), scallops (Amusium pleuonectes, Mimachlamys nobilis, Argopecten irradians), oysters Crassostrea rivularis), sea snail (Haliotis tuberculate) and crab (Zosimus aeneus), among other edible marine organisms (Bricelj \& Shumway, 1998; Tan \& Ransangan, 2015).

PST intoxication results from ingestion of seafood containing potent algal toxins, the parent molecule of which is saxitoxin (STX), which acts by blocking sodium channels in excitable membranes of cells, notably neurons (Pellegrino et al., 1984). Clinical symptoms of PST intoxication in mild cases begin with circumoral paresthesia that slowly spreads to the face, neck, fingers, and other parts, and dizziness, nausea. Symptoms usually begin 2 12 hours after ingestion of the contaminated products, with gradual resolution over 24 hours (FAO/IOC/WHO, 2004). Severe poisoning results in muscle paralysis, dyspnea, and death from respiratory paralysis (FAO/IOC/WHO, 2004), with symptom onset 2-12 hours after consumption of contaminated shellfish. An antidote for PST intoxication has yet to be found.

STX is a trialkyl tetrahydropurine derivative (Figure 1) that is soluble in water and has thermal and acid stability (Wang, 2008). Wiese et al. (2010) collected 57 PST derivatives, 20 of which can be extracted from shellfish. The toxic potencies of individual PSTs are expressed in relation to STX, and the relevant toxicity-equivalence factors (TEFs) are shown in Table 1 (ESFA, 2009; Van de Riet et al.,2009). International regulation limits for PSTs in shellfish are set at $800 \mu \mathrm{g}$ STX eq./kg shellfish meat (Vale \& Taleb, 2005; EFSA, 2009).

In recent years, outbreaks of human PSP have occurred in coastal areas around the world, particularly in countries with Atlantic and Pacific coastlines. More than 2100 cases of PSP with 120 deaths were reported in the Philippines between 1983 and 2002 (Visciano et al., 2016.Ching et al., 2015). Hundreds of other PSP cases have been reported in Asia over the past decade (Nicolas et al., 2017, Ching et al., 2015). China has experienced many PSP cases and fatalities in coastal cities. Between 1991 and 2003, the coastal city of Lianyungang City in China's Jiangsu Province reported 11 
PSP events, which together sickened 40 individuals and resulted in 8 fatalities, and coastal Fujian Province in S.E. China reported a PSP incident involving 164 cases in 2017 (Xiang-Tian et al. ,2005; Zhou et al., 2013; Chen et al., 2018). Additionally, the southern coast of China has experienced sporadic outbreaks of PSP (Anderson, 1996) and, at the turn of the 21 st century, up to $30 \%$ of shellfish samples containedalgal toxins in the Shenzhen area of the South China Sea (Jiang et al., 2003), where the predominant PSP source was the dinoflagellate Alexandrium pacificu (Liu et al., 2021). In March 2005, Shenzhen's neighbor Hong Kong experienced 36 clusters of shellfish poisoning related to consumption of fresh scallops (Atrina vexillum). Since Shenzhen and Hog Kong have a combined a population of 20 million residents, all of whom are at risk for exposure to PSP, the present study assesses the current level of toxin contamination of edible shellfish and the extent of residential dietary exposure to these biologically dangerous substances.

\section{Material And Methods 2.1 Sampling}

Every month from March 2019 to February 2020, shellfish samples were collected from the Buji seafood wholesale market in Luohu, which supplies $90 \%$ of shellfish consumed in Shenzhen. Other shellfish were collected from local retail stores. In total, 188 shellfish samples of 14 species were collected, including: Chlamys nobilis (scallop), Crassostrea rivularis (oyster), Perna viridis (mussel), Paphia undulata (clam), Atrina pectinate (bivalve), Babylonia areolate (sea snail), Scapharca broughtoni (clam), Scapharca subcrenata (bivalve), Meretrix meretrix (clam), Sinonovacula constricta (razor clam), Ruditapes philippinara (clam), Patinopecten yessoensis (scallop), Solen gouldi (bivalve), and Mytilus edulis (mussel).

Since the year-round availability of three shellfish species (Solen gouldi, Mytilus edulis and Scapharca subcrenata) was limited, their sample sizes were small relative that of other species.

\subsection{Reagents}

Methanol, acetonitrile, and formic acid were purchased from Merck (Darmstadt, Germany).

Methylene chloride was obtained from Damao Chemical Reagent Factory (Tianjin, China). Water was distilled and passed through a MilliQ water purification system (Millipore, Burlington, Mass. USA). Ammonium formate was purchased from Sigma (Bangalore, India). PST standard reagents (C1, C2, dcGTX2, dcGTX3, dcNEO, dcSTX, GTX1, GTX2, GTX3, GTX4, GTX5, STX, NEO) were purchased from Bedford Institute of Oceanography (Dartmouth, Nova Scotia, Canada).

\subsection{Toxin extraction}

Shellfish samples were cleaned with fresh water, emoved from their shells, and rinsed again with MiliQ water to remove silt from the flesh. Shellfish meat and viscera ( $200 \mathrm{~g}$ of each batch) was removed and homogenized. An $5 \mathrm{~g}$ aliquot of homogenized sample was transferred to a centrifuge tube, $8 \mathrm{~mL}$ of $0.5 \%$ formic acid solution added, for vortex-mixed for $5 \mathrm{~min}$, ultrasonically extracted for $10 \mathrm{~min}$, followed by centrifugation at $9500 \mathrm{rpm} / \mathrm{min}$ for $10 \mathrm{~min}$. The suspension was immersed in $0.5 \%$ formic acid solution to $10 \mathrm{~mL}$. Two $\mathrm{mL}$ of this mixture were added to $5 \mathrm{~mL}$ dichloromethane, vortex-mixed for $3 \mathrm{~min}$, and then centrifuged for $5 \mathrm{~min}$ at $9500 \mathrm{rpm}$. Then, $1 \mathrm{~mL}$ suspension was passed through a C18 solid-phase extraction cartridge (Waters, Millford, Mass., USA) that had been activated by adding $3 \mathrm{~mL}$ acetonitrile 
and $3 \mathrm{~mL} 0.5 \%$ formic acid solution in that order, and then immersed in $1.5 \mathrm{~mL} 0.5 \%$ formic acid solution. The eluate was collected, adjusted to $6 \mathrm{~mL}$ acetonitrile solution, and vortexed. The resulting solution was allowed to rest for 30 $\min$ in a $-4^{\circ} \mathrm{C}$ refrigerator, then centrifuged at $9500 \mathrm{t} / \mathrm{min}$ for $5 \mathrm{~min}$, passed through $0.22 \mu \mathrm{m}$ nylon syringe filter and collected in a brown test tube.

\subsection{Detection and quantification of PSTs}

Firstly, a chromatographic analysis was performed with a Nexera X2 HPLC system (Shimadzu, Kyoto, Japan) comprising a degassing unit, an auto-sampler and a micro binary pump and equipped with a Waters Amide column $\left(2.1 * 100 \mathrm{~mm} \otimes 3.5 \mu \mathrm{m}\right.$, Waters, USA). The temperature of the column was set at $40^{\circ} \mathrm{C}$. The injection volume was $5 \mu \mathrm{L}$, and the flow rate was set to $0.5 \mathrm{~mL} / \mathrm{min}$ in all time. The mobile phase consisted of two eluates: $\mathrm{A}(1 \mathrm{mmol} / \mathrm{L}$ ammonium formate solution) and $B$ (acetonitrile), both of which contained $1.3 \mathrm{mmol} / \mathrm{L}$ formic acid. The elution was performed starting with 5\% A for 2 min, increasing to $15 \%-30 \%$ for $16 \mathrm{~min}$, and finally $5 \%$ A for 2.5 min for column reequilibration. PSP toxins were detected by mass spectrometry analysis using a Shimadzu 8050 series mass spectrometer equipped with an electrospray interface set in the positive ionization mode (ESI+). PSP toxins (and their corresponding PubChem CID) included: neo-dc saxitoxin (dcNEO, 100962170), gonyautoxin 5 (GTX5, 49789073), neosaxitoxin (NEO, 135562690 ), dc saxitoxin (dcSTX ,101936522), saxitoxin (STX, 56947150). A negative ionization mode (ESI $)$ ) was used to detect: N-sulfocarbamoyl-gonyautoxin-2 and -3(C1,2, 49789085), and other gonyautoxins, including dcGTX2 (101034662), GTX1 (135061918), GTX2 (101650338), GTX4 (440699577), GTX3 (46217347), and dcGTX3(101034664). The multiple reaction monitoring (MRM) mode was used, with specific transition parameters as shown in Table 2. The capillary voltage was $4000 \mathrm{~V}$, the nebulizer gas flow rate was $3 \mathrm{~L} / \mathrm{min}$, the drying gas flow rate was $10 \mathrm{~L} / \mathrm{min}$, and the temperature of the ion source was $300^{\circ} \mathrm{C}$. The limits of detection (LOD, $\left.\mu \mathrm{g} / \mathrm{kg}\right)$ were dcNEO (24), GTX5 (60), NEO (30), dcSTX (30), STX (30), C1(40.8), C2 (24), dcGTX2 (42), GTX1 (38.4), GTX2 (28.8), GTX4 (48), GTX3 (48, dcGTX3(48).

\subsection{Dietary exposure assessment}

Dietary exposure to shellfish toxins was performed by multiplying shellfish PST value and amount of shellfish consumed divided by the target population mean body weight (WHO, 2009; Wong, 2013).

\subsubsection{Consumption data}

The consumption data and mean body weight of the target population were obtained from the individual-based Shenzhen Food Consumption Survey 2008 (SZFCS 2008), which was conducted by the Shenzhen Center for Disease Control and Prevention (SZCDC). A three-stage cluster sampling was performed taking account of local population flow and density, together with geographic and economic characteristics (Yang et al. 2014). Referring to the sampling principles of China National Health and Nutrition Survey (2002), 244 households were selected throughout 4 urban regions and 2 rural regions, a total of 853 individuals was included. Food consumption data were assessed by a continuous 3-day door-to-door interview, which included weighing that was consumed at home and using a 24-h dietary-recall questionnaire to record food intake outside of the home.

\subsubsection{PSTs contamination data}


Sample PST contamination data were assessed using liquid chromatography-tandem mass spectrometry (LCMS/MS). Since the data were left-censored, the protocol for assigning concentration values to ND results was applied in this study. In a lower bound (LB) scenario, 0 was used to substitute for ND results (FAO/WHO,2009; EFSA,2010); while, in an upper bound (UB) scenario, 1/2 LOD was used to substitute for ND results.

\section{Results}

\subsection{Detection of PSTs in shellfish}

Among 188 shellfish samples, 26 samples (13.8\%) detected positive for PSTs (Table 3). Samples of the Noble scallop Chamys nobilis had the highest positive rate: 10 of 34 samples (29.4\%) were PST-positive. High-positive rates were also recorded for the oyster Crassostrea rivularis (5/18, 21.7\%) and the Asian green mussel Perna viridis (4/20, 20\%). PSTs were not detected in samples of 7 shellfish species (Meretrix meretrix, Sinonovacula constricta, Ruditapes philippinara, Patinopecten yessoensis, Solen gouldi and Mytilus edulis.

Nan'ao or Nanao, formerly romanized Namoa, is an island and county of the prefecture-level city of Shantou in Guangdong Province, China.

Shellfish PST contamination varied by the source location in China (Figure 2). Most contamination was detected in samples taken from waters around Nan'ao island (7/17, 41.2\%), followed by Huidong (6/31, 19.4\%) and Zhanjiang $(6 / 31,19.4 \%)$. Shellfish samples from coastal Dianbai, Shantung, and Yangjiang were PST-negative. Only samples distributed in spring and winter were positive for PSTs: the highest detected rate was in March (5/15, 33.3\%), followed by December $(5 / 16,34.3 \%)$ and January $(5 / 16,31.3 \%)$. Samples collected from June to October 2019 were free from PSTs contamination. Detected rates among the time-sampled groups differed significantly by Fisher exact test $(p<0.01)$.

\subsection{Concentration of PSTs in shellfish}

The concentration PSTs $(n=13)$ was quantified for each seafood sample. The number of samples tested and the distribution of individual PSTs is shown in Figure 3. Most samples were C1 positive (19/188, 10.1\%), with the widest concentration range of $65.0 \sim 1596.5 \mu \mathrm{g} / \mathrm{kg}$, followed by C2 (14/188, 7.5\%), GTX5 (8/188, 4.3\%) and others. NEO, STX, CTX3, GTX4 was not detected in any sample. The concentration ranges for individual PSTs are summarized in Figure 4. Individual PST concentration was converted to the STX-equivalent by multiplying the appropriate toxic equivalent factors (Shin et al., 2018) accordingly to obtain the total PST concentration/sample.

Among all samples, mean PST concentration ranged from 10.85(LB) 134.06(UB) $\mu \mathrm{g}$ STX eq. $/ \mathrm{kg}$, with maximum values ranging from $715.60(\mathrm{LB})$ to $796.00(\mathrm{UB}) \mu \mathrm{g}$ STX eq. $/ \mathrm{kg}$. Both mean and maximum PST concentrations were highest in Chlamys nobilis and samples obtained from Nan'ao. Samples collected in March and April contained similar mean and maximum PSTs concentrations, and these values were higher than in samples collected in other months. Detailed PST concentration sets for all samples, by shellfish species, sources, and time of sampling, are integrated in Table 4.

\subsection{Acute Dietary Exposure Assessment}

International guidance dictates that large portions of shellfish should be used to conduct an acute dietary exposure assessment (WHO, 2009). A large portion was estimated as $139.2 \mathrm{~g} /$ day in the present study, which corresponded to 
$\mathrm{P}_{99}$ shellfish consumption data of individuals included in SZFCS 2008. Consumption data and adult mean body weight $(60.2 \mathrm{~kg})$ were acquired from SZFCS 2008. Both upper and lower bounds of maximum PST concentrations were used to assess the acute dietary exposure level. In studies conducted by the IOC/WHO Expert Consultation on Biotoxins in Molluscan Bivalves, the PST toxicological reference value of provisional Low Observed Adverse Effect Level( LOAEL) was established as $2.0 \mu \mathrm{g} / \mathrm{kg}$ bw. A safety factor of 3 was used to drive an Acute Reference Dose (ARfD ) of $0.7 \mu \mathrm{g}$ STX eq./ $\mathrm{kg}$ bw because a wide spectrum of people report shellfish poisoning, and mild illness is readily reversible (FAO/IOC/WHO, 2004; Picot et al.,2011; Toyofuku, 2006). On the other hand, the European Food Safety Authority (EFSA) established a lower LOAEL $(1.5 \mu \mathrm{g} / \mathrm{kg}$ bw) based on $\sim 500$ reported PSP cases; an ARfD of 0.5 $\mu \mathrm{g}$ STX eq./kg bw was proposed subsequently using a safety factor of 3 (EFSA, 2009).

Data for the acute dietary exposure level with respect to individual seafood species are summarized in Figure 5. The highest acute dietary exposure value was $1.84 \mu \mathrm{g} \mathrm{STX} \mathrm{eq./kg} \mathrm{bw/day} \mathrm{using} \mathrm{the} \mathrm{upper} \mathrm{bound} \mathrm{of} \mathrm{the} \mathrm{maximum}$ contamination value of Chlamys nobilis, which corresponded to approximately 2.6 3.7 times the ARfD established by FAO/IOC/WHO and ESFA respectively. In the lower bound scenario, the acute dietary exposure value for Chlamys

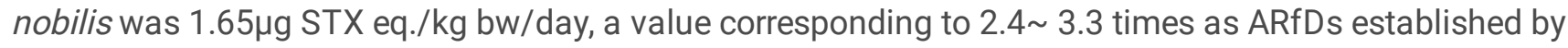
$\mathrm{FAO} / \mathrm{IOC} / \mathrm{WHO}$ and ESFA respectively. The acute dietary exposure values of other species were lower than $0.5 \mu \mathrm{g}$ STX eq./kg bw.

\subsection{Chronic Exposure Assessment}

For the chronic exposure assessment of PSTs in shellfish, both lower and upper bounds (LB, UB) of mean concentrations were used. According to SZFCS 2008, the mean shellfish consumption was $4.82 \mathrm{~g} /$ day. The PST chronic dietary exposure value of all samples ranged from 0.009 (LB) to $0.0107(\mathrm{UB}) \mu \mathrm{g} \mathrm{STX}$ eq./kg bw/day. To estimate an extreme situation, chronic dietary exposure using $P_{99}$ shellfish consumption data(139.2 g/day) were also assessed, with results ranging from 0.0251 (LB) to $0.31(\mathrm{UB}) \mu \mathrm{g}$ STX eq./ $\mathrm{kg}$ bw/day. Tolerable daily intake (TDI) is considered to be the standard reference for chronic exposure assessment (Shin et al., 2018); however, no such reference has been established by reliable authorities or formal organizations. Therefore, in this study, chronic exposure values were compared to ARfDs by EFSA and FAO/IOC/WHO. Chronic dietary exposure values using mean shellfish consumption data were much lower than recommended ARfD. In the estimated extreme scenario, even the upper-bound chronic dietary exposure value was $0.44 \sim 0.62$ times the EFSA ARfD. Chronic dietary exposure assessment was also analyzed for different species as summarized in Table 5.

\section{Discussion}

The present study used mass spectrometry to detect and quantify PSTs in marine species sold for human consumption in Shenzhen city in southern China. Seafood samples included the viscera, human consumption of which was identified in neighboring Hong Kong as the highest risk factor for shellfish poisoning (Chung et al., 2006). We found that most seafood samples had lower concentrations of PSTs than the corresponding limits of detections. Among 13 PST derivatives, C1, C2, GTX1, GTX2, dcGTX2, dcGTX3, GTX5, dcNE0, and dcSTX were detected in seafood samples sold in Shenzhen, with $\mathrm{C} 1$ and $\mathrm{C} 2$ the most predominant components. These results are similar to those of Liu and colleagues (2017), who studied PSTs in phytoplankton and shellfish samples from the Bohai Sea in northern China. They found that toxic Alexandrium spp. and Gymnodinium catenatum were potential producers of PSTs, and most low-PST-content phytoplankton samples were C1/C2- positive.

The concentration of PSTs differs in shellfish species (Brieelj et al., 1990) and sources. We found that 8 of 14 species were contaminated, particularly Chlamys nobilis (Noble scallop) with PST concentration of 715.6(LB) 796(UB) $\mu \mathrm{g}$ 
STX eq./kg, a value at the edge of the international regulation limit of $800 \mu \mathrm{g}$ STX eq. $/ \mathrm{kg}$ (Vale \& Taleb, 2005; EFSA,2009). Studies by Fan and Xiao-Yan (2006) and Jiang and colleagues (2000) showed PST accumulation in Chlamys nobilis was greater than in Perna viridis (Asian green mussel). We found that shellfish collected from Nan'ao contained higher than PST concentrations than samples obtained from other locations. PST-positive shellfish from all locations were highest from December to May match months with those reported in the Results. These findings are comparable with seasonal variation in shellfish concentrations of PSTs (Taleb et al., 2001; Harley et al., 2020), which are mostly detected in spring, early summer, and autumn in the South China Sea (Yao et al., 2019).

Acute dietary exposure of Chinese citizens to shellfish PSTs was determined in the present study to assess the risk of paralytic shellfish poisoning (PSP). Expert assessment of several PSP case series showed that mild cases generally had ingested PST levels of $2-30 \mu \mathrm{g} / \mathrm{kg}$ bw, while more severe cases resulted from intake levels of $>10-300 \mu \mathrm{g} / \mathrm{kg} \mathrm{bw}$

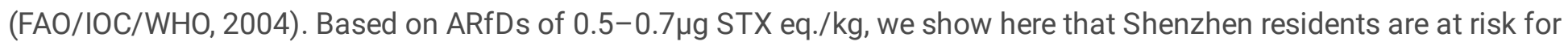

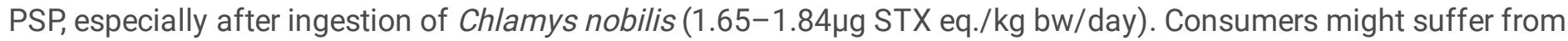
PSP mild case symptoms such as dizziness, nausea and a pricking sensation of the tongue and lips. Consumption of other shellfish species on sale in Shenzhen requires ongoing PST monitoring but presently appears to be safe.

The Tolerable Daily Intake (TDI) for PSTs has not been established because chronic toxicity studies are unavailable (Visciano P, et al., 2016); thus, we used the Acute Reference Dose (ARfD) as a reference limit for chronic dietary exposure assessment. The chronic exposure value ranged from $0.0009 \sim 0.0107 \mu \mathrm{g}$ STX eq. $/ \mathrm{kg}$ bw/day using mean shellfish consumption data, a level much lower than the ARfD. To assess the chronic dietary exposure in a more conservative way, we used $\mathrm{P}_{99}$ shellfish consumption data to exaggerate the chronic dietary exposure level, the results of which were $0.0251 \sim 0.31 \mu \mathrm{g} \mathrm{STX} \mathrm{eq./kg} \mathrm{bw/day,} \mathrm{values} \mathrm{that} \mathrm{were} \mathrm{also} \mathrm{lower} \mathrm{than} \mathrm{the} \mathrm{recommended} \mathrm{ARfDs.}$

There are limitations in this study, including outdated (2008) local dietary survey data and population data (9.5 million vs. 12.5 million today); uncertainties associated with dietary exposure assessment, such as the accuracy of consumption data; the limited amount of sample contamination data; using 0 and 1/2 LOD to substitute ND values as the lower and upper bounds; and the lack of a proper reference for chronic exposure assessment, which could cause the outcomes to be under- or over-estimated.

Ongoing studies should be conducted on the diet, nutrition and health status of the Shenzhen population, with dietary PST exposure assessments based on contemporary population figures and stratified consumption data. Since species like Solen gouldi and Mytilus edulis are marketed in only specific months, periodic long-term toxin screening studies are needed to develop an in-depth picture of temporal changes in shellfish contamination. Studies to understand the habitats of shellfish species prone to high concentrations of PSTs are also needed.

\section{Conclusions}

We found that none of the seafood samples contained levels of total PSTs that exceeded international regulation limits. However, dietary exposure results indicated that Shenzhen residents are at risk for acute paralytic shellfish toxins poisoning. Local authorities should strengthen the screening of shellfish for PSTs before they are placed on the market, especially in spring and winter, thereby ensuring product quality and control of high-risk species, notably Chlamys nobilis, Crassostrea rivularis, Perna viridis, among other species. Meanwhile, the Shenzhen PST exposure levels determined in in this study might serve as a basis for establishing local limit values for shellfish consumption.

\section{Abbreviations}


ARfD: Acute Reference Dose; EFSA: European Food and Safety Association; FAO: Food and Agriculture Organization; IOC: Intergovernmental Oceanographic Commission of UNESCO; LB: Lower bound; LOD(s): Limits of detection; LOAEL: Low Observed Adverse Effect Level; PSP: Paralytical shellfish poisoning; PST(s): Paralytic shellfish toxin(s); STX区 saxitoxin; SZCDCヌShenzhen Center for Disease Control and PreventionヌSZFCS 2008:Shenzhen Food Consumption Survey 2008; TEF(s): Toxicity-equivalence Factors; TDI: Tolerable daily intake; UB囚Upper bound; WHO: World Health Organization.

\section{Declarations}

\section{Ethical approval and consent to participate}

No approval of research ethics committees was required to accomplish the goals of this study because experimental work was conducted with an unregulated invertebrate species. Not applicable.

\section{Consent to publish}

Not applicable.

\section{Availability of data and material}

The datasets used and/or analysed during the current study are available from the corresponding author on reasonable request.

\section{Competing interests}

The authors declare that they have no competing interests.

\section{Funding}

This work was supported by the Shenzhen Basic Research Plan [JCYJ20180508152311822], the National Key Research and Development Program of China (2018FY100201, 2019YFC407900), Shenzhen Key Medical Discipline Construction Fund (SZXK069), and Sanming Project of Medicine in Shenzhen (SZSM201611090).

\section{Authors' contributions}

Yan Zhou: Writing-Original draft preparation, Visualization, Formal analysis. Shenpan Li: Methodology. Jianying Zhang: Data curation. Jinzhou Zhang: Project administration, Methodology. Zhou Wang. Methodology, Data curation. Liubo Pan: Methodology, Data curation. Baiqiang Huang: Conceptualization, Methodology. Ke Huang: Data curation. Xiao Chen: Methodology. Qionghui Zhao: Data curation. Tianjiu Jiang: Methodology, Funding acquisition. Jianjun Liu: Project administration, Conceptualization, Methodology, Supervision, Funding acquisition.

\section{References}


1. Anderson DM, Kulis DM, Qi YZ, Zheng L, Lu S, Lin YT (1996) Paralytic shellfish poisoning in southern China. Toxicon 34(5):579-590. https://doi.org/10.1016/0041-0101(95)00158-1

2. Asakawa, M., Beppu, R., Ito, K., Tsubota, M., Takayama, H., \& Miyazawa, K. (2006). Accumulation of paralytic shellfish poison (PSP) and biotransformation of its components in oysters, Crassostrea gigas, fed with the toxic dinoflagellate Alexandrium tamarense. Journal of the Food Hygienic Society of Japan, 47(1), 28-32.

https://doi.org/10.3358/shokueishi.47.28

3. Brieelj, V.M., Lee, J.H., Allderson, D.M.(1990). Uptake kinetics of paralytic shellfish toxins from the dinoflagellate Alexandrium fundyense in the mussel Mytilus edulis. Marine Ecology Progress Series, 63 (2/3), 177-188. https://doi.org/10.3354/meps063177

4. Bricelj, V.M., Shumway, S.E. (1998). Paralytic Shellfish Toxins in Bivalve Molluscs: Occurrence, Transfer Kinetics, and Biotransformation. Reviews in Fisheries Science, 6(4),315-383.

https://doi.org/10.1080/10641269891314294.

5. Chen, J. Z., Hong, S. P., Cai, M. R., Chen, L., \& Zhang, T. L. (2018). [Investigation of outbreaks of foodborne diseases caused by paralytic shellfish poisoning]. Chinese Journal of Food Hygiene, 30(4), 445-448. Chinese. https://doi.org/10.13590/j.cjfh.2018.04.022

6. Ching, P. K., Ramos, R. A., de los Reyes, V. C., Sucaldito, M. N., \& Tayag, E. (2015). Lethal paralytic shellfish poisoning from consumption of green mussel broth, Western Samar, Philippines, August 2013. Western Pacific surveillance and response journal, 6(2), 22-26. https://doi.org/10.5365/WPSAR.2015.6.1.004

7. Chung PH, Chuang SK, Tsang T (2006) Consumption of viscera as the most important risk factor in the largest outbreak of shellfish poisoning in Hong Kong, 2005. Southeast Asian J Trop Med Public Health 37(1):120-125. PMID: 16771223

8. European Food Safety Authority (EFSA) (2009). Scientific opinion of the panel on contaminants in the food chain on a request from the European commission on marine biotoxins in shellfish - Summary on regulated marine biotoxins. EFSA Journal, 1306, 1-23. https://doi.org/10.2903/j.efsa.2009.1306

9. European Food Safety Authority (EFSA) (2010). Management of left-censored data in dietary exposure assessment of chemical substances. EFSA Journal, 8(3),1557. https://doi.org/10.2903/j.efsa.2010.1557

10. Fan, F., \& Xiao-Yan, L. (2006). [Identification of indicator species of paralytic shellfish poison]. Chinese Journal of Food Hygiene, 18(6),542-544. https://doi.org/10.3969/j.issn.1004-8456.2006.06.014.

11. FAO/IOC/WHO (2004). Report of the Joint FAO/IOC/WHO ad hoc Expert Consultation on Biotoxins in Bivalve Molluscs. Norway. FAO/IOC/WHO, 1-31.

https://www.who.int/foodsafety/publications/chem/biotoxin_report_en.pdf.

12. Harley, J. R., Lanphier, K., Kennedy, E. G., Leighfield, T. A., Bidlack, A., Gribble, M. O., \& Whitehead, C. (2020). The Southeast Alaska Tribal Ocean Research (SEATOR) Partnership: Addressing Data Gaps in Harmful Algal Bloom Monitoring and Shellfish Safety in Southeast Alaska. Toxins, 12(6), 407. https://doi.org/10.3390/toxins12060407

13. Jiang T, Chen J, Zou Y, Liu J, Yang W (2003), [Paralytic shellfish toxins in shellfish from the coast of high frequent harmful algae blooms occurrence areas in East China Sea and South China Sea]. Ying Yong Sheng Tai Xue Bao, 14(7),1156-60. Chinese. PMID: 14587342

14. Jiang, T. J., Yin, Y. W., Luo, Y. M., Chen, J. F., \& Zao, Q. Y. (2000). [Paralytic shellfish toxins in shellfish from Daya Bay and Dapeng Bay]. Marine Enviornmental Science, 19(2),1-5. Chinese. https://doi.org/10.3969/j.issn.10076336.2000.02.001

15. Lin, X. T., Zhang, M. S., Wang, Z. J., \& Zhang, Y. Y. (2005). [Analysis of poisoning characteristics of paralytic shellfish poison in Haizhou Bay of Lianyungang, Jiangsu Province]. Chinese Journal of Food Hygiene, 17(3), 243246. Chinese. https://doi.org/10.3969/j.issn.1004-8456.2005.03.011

Page $10 / 22$ 
16. Liu, R.Y., Ma, D.Y., \& Liang, Y. B. (2004). [Research progress on biosynthesis of phycotoxinsparalytic shellfish poisoning]. Marine Environmental Science, 23(4),71-75. Chinese. https://doi.org/10.3969/j.issn.10076336.2004.04.019

17. Liu, Y., Yu, R. C., Kong, F. Z., Chen, Z. F., Dai, L., Gao, Y., Zhang, Q. C., Wang, Y. F., Yan, T., \& Zhou, M. J. (2017). Paralytic shellfish toxins in phytoplankton and shellfish samples collected from the Bohai Sea, China. Marine pollution bulletin, 115(1-2), 324-331. https://doi.org/10.1016/j.marpolbul.2016.12.023

18. Liu, Y., Chen, Z., Gao, Y., Zou, J., Lu, S., \& Zhang, L. (2021). Identifying the Source Organisms Producing Paralytic Shellfish Toxins in a Subtropical Bay in the South China Sea. Environmental science \& technology, 55(5), 31243135. https://doi.org/10.1021/acs.est.0c06991

19. Nicolas, J., Hoogenboom, R. L. A.P., Hendriksen, P.J.M, et al.(2017). Marine biotoxins and associated outbreaks following seafood consumption: prevention and surveillance in the 21st century. Global Food Security, 15,11-21. https://doi.org/10.1016/j.gfs.2017.03.002

20. Pellegrino, R. G., Spencer, P. S., \& Ritchie, J. M. (1984). Sodium channels in the axolemma of unmyelinated axons: a new estimate. Brain research, 305(2), 357-360. https://doi.org/10.1016/0006-8993(84)90442-6

21. Shin, C., Jo, H., Kim, S. H., \& Kang, G. J. (2018). Exposure assessment to paralytic shellfish toxins through the shellfish consumption in Korea. Food research international, 108, 274-279.

https://doi.org/10.1016/j.foodres.2018.03.061

22. Taleb, H., Vale, P., Jaime, E., \& Blaghen, M. (2001). Study of paralytic shellfish poisoning toxin profile in shellfish from the Mediterranean shore of Morocco. Toxicon, 39(12), 1855-1861. https://doi.org/10.1016/s00410101(01)00167-2

23. Tan, K. S., \& Ransangan, J. (2015). Factors influencing the toxicity, detoxification and biotransformation of paralytic shellfish toxins. Reviews of environmental contamination and toxicology, 235, 1-25. https://doi.org/10.1007/978-3-319-10861-2_1

24. Toyofuku, H. (2006). Joint FAO/WHO/IOC activities to provide scientific advice on marine biotoxins (research report). Marine pollution bulletin, 52(12), 1735-1745. https://doi.org/10.1016/j.marpolbul.2006.07.007

25. Vale, P., \& Taleb, H. (2005). Assessment of the quantitative determination of paralytic shellfish poisoning toxins by pre-column derivatization and elimination of interfering compounds by solid-phase extraction. Food additives and contaminants, 22(9), 838-846. https://doi.org/10.1080/02652030500195247

26. Van de Riet, J. M., Gibbs, R. S., Chou, F. W., Muggah, P. M., Rourke, W. A., Burns, G., Thomas, K., \& Quilliam, M. A. (2009). Liquid chromatographic post-column oxidation method for analysis of paralytic shellfish toxins in mussels, clams, scallops, and oysters: single-laboratory validation. Journal of AOAC International, 92(6), 16901704. PMID. 20166587.

27. Visciano, P., Schirone, M., Berti, M., Milandri, A., Tofalo, R., \& Suzzi, G. (2016). Marine Biotoxins: Occurrence, Toxicity, Regulatory Limits and Reference Methods. Frontiers in microbiology, 7, 1051. https://doi.org/10.3389/fmicb.2016.01051

28. Wang, D. Z. (2008). Neurotoxins from marine dinoflagellates: a brief review. Marine drugs, 6(2), 349-371. https://doi.org/10.3390/md20080016

29. Wiese, M., D'Agostino, P. M., Mihali, T. K., Moffitt, M. C., \& Neilan, B. A. (2010). Neurotoxic alkaloids: saxitoxin and its analogs. Marine drugs, 8(7), 2185-2211. https://doi.org/10.3390/md8072185

30. World Health Organization (WHO) (2009). Dietary exposure assessment of chemicals in food (Chap. 6). Principles and methods for the risk assessment of chemicals in food. Environmental Health Criteria 240. Geneva: FAO/WHO. International Programme on Chemical Safety (IPCS). http://www.who.int/ipcs/food/principles. 
31. Wong WW, Chung SW, Chan BT, Ho YY, Xiao Y (2013) Dietary exposure to inorganic arsenic of the Hong Kong population: results of the first Hong Kong total diet study. Food chemical toxicology 51:379-385. https://doi.org/10.1016/j.fct.2012.10.010

32. Yang, M., Jiang, L., Huang, H., Zeng, S., Qiu, F., Yu, M., Li, X., \& Wei, S. (2014). Dietary exposure to aluminium and health risk assessment in the residents of Shenzhen, China. PloS one, 9(3), e89715. https://doi.org/10.1371/journal.pone.0089715

33. Yao, J., Jin, W., Li, D., Xu, D., Wen, S., Liu, R., Liang, Y., \& Lu, S. (2019). Geographical distribution and seasonal variation in paralytic shellfish toxins in the coastal water of the South China Sea. Toxicon, 168, 67-75. https://doi.org/10.1016/j.toxicon.2019.06.221

34. Zhou, J., Zhou, Z. F., Deng, K. J., \& Jiang, L. X. (2013).[ A food poisoning caused by shellfish toxins]. Occupation and Health, 29(16),2025-2026.Chinese. https://doi.org/cnki:sun:zyjk.0.2013-16-023

\section{Tables}

Table 1

The toxic factor and standard limit of PSTs

\begin{tabular}{|lll|}
\hline PST & TEF & Limit \\
dcNEO & 0.4 & \multirow{2}{*}{ 800 $\mu \mathrm{g}$ STX eq./kg } \\
GTX5 & 0.1 & \\
NEO & 1 \\
\hline dcSTX & 1 \\
STX & 1 \\
\hline C1 & 0.01 \\
\hline C2 & 0.1 \\
\hline dcGTX2 & 0.2 \\
\hline GTX1 & 1 \\
\hline GTX2 & 0.4 \\
\hline GTX4 & 0.7 \\
\hline GTX3 & 0.6 \\
\hline dcGTX3 & 0.4 \\
\hline
\end{tabular}

Table 2

Mass spectrum parameters, limits of detection and limits of quantification for PSTs 


\begin{tabular}{|c|c|c|c|c|c|}
\hline PST & $\begin{array}{l}\text { Precursor-product } \\
\text { ions }\end{array}$ & $\begin{array}{l}\text { Positive/ } \\
\text { Negative }\end{array}$ & $\begin{array}{l}\text { Linear } \\
\text { range } \\
(\mathrm{ng} / \mathrm{mL})\end{array}$ & $\begin{array}{l}\text { Limit of } \\
\text { detection }(\mu \mathrm{g} / \mathrm{kg})\end{array}$ & $\begin{array}{l}\text { Limit of } \\
\text { quantification }(\mu \mathrm{g} / \mathrm{kg})\end{array}$ \\
\hline dcNEO & 273.1-126.0 & ESI+ & $4 \sim 80$ & 24 & 48 \\
\hline GTX5 & $380.1-300.1$ & ESI+ & $10 \sim 500$ & 60 & 120 \\
\hline NEO & $316.0-220.0$ & ESI+ & $10 \sim 500$ & 30 & 60 \\
\hline dcSTX & $257.1-126.0$ & ESI+ & $5 \sim 200$ & 30 & 60 \\
\hline STX & $300.0-204.0$ & ESI+ & $5 \sim 200$ & 30 & 60 \\
\hline C1 & $474.0-357.0$ & ESIX & $6.8 \sim 270$ & 40.8 & 81.6 \\
\hline $\mathrm{C} 2$ & 474.0-121.9 & ESI区 & $4 \sim 80$ & 24 & 48 \\
\hline dcGTX2 & $351.1-333.1$ & ESIX & $7 \sim 275$ & 42 & 84 \\
\hline CTX1 & $410.1-367.1$ & ESI区 & $6.4 \sim 254$ & 38.4 & 76.8 \\
\hline GTX2 & $394.0-351.1$ & ESIX & $4.7 \sim 187$ & 28.8 & 56.4 \\
\hline GTX4 & $410.1-367.1$ & ESI区 & $8 \sim 160$ & 48 & 96 \\
\hline GTX3 & $394.0-351.1$ & ESI区 & $8 \sim 160$ & 48 & 96 \\
\hline dcGTX3 & $351.1-333.1$ & ESIQ & $8 \sim 160$ & 48 & 96 \\
\hline
\end{tabular}

Table 3

PST presence and absence of detected PST contamination in shellfish samples $(n=188)$ 


\begin{tabular}{|c|c|c|c|c|c|}
\hline & $\mathrm{n}$ & $\%$ & $\mathrm{n}$ & $\%$ & \\
\hline Species & & & & & 0.053 \\
\hline Chlamys nobilis & 10 & 29.41 & 24 & 70.59 & \\
\hline Crassostrea rivularis & 5 & 21.74 & 18 & 78.26 & \\
\hline Perna viridis & 4 & 20.00 & 16 & 80.00 & \\
\hline Paphia undulata & 3 & 7.50 & 37 & 92.50 & \\
\hline Atrina pectinate & 1 & 8.33 & 11 & 91.67 & \\
\hline Babylonia areolata & 1 & 10.00 & 9 & 90.00 & \\
\hline Scapharca broughtoni & 1 & 33.33 & 2 & 66.67 & \\
\hline Scapharca subcrenata & 1 & 50.00 & 1 & 50.00 & \\
\hline Meretrix meretrix & 0 & 0 & 18 & 100 & \\
\hline Sinonovacula constricta & 0 & 0 & 11 & 100 & \\
\hline Ruditapes philippinara & 0 & 0 & 6 & 100 & \\
\hline Patinopecten yessoensis & 0 & 0 & 5 & 100 & \\
\hline Solen gouldi & 0 & 0 & 2 & 100 & \\
\hline Mytilus edulis & 0 & 0 & 2 & 100 & \\
\hline Sources & & & & & 0.074 \\
\hline Nan'ao & 7 & 41.18 & 10 & 58.82 & \\
\hline Huidong & 6 & 19.35 & 25 & 80.65 & \\
\hline Zhanjiang & 6 & 19.35 & 25 & 80.65 & \\
\hline Aotou & 2 & 9.52 & 19 & 90.48 & \\
\hline Guangxi & 2 & 12.50 & 14 & 87.50 & \\
\hline Fukien & 1 & 5.88 & 16 & 94.12 & \\
\hline Hainan & 1 & 10.00 & 9 & 90.00 & \\
\hline Zhuhai & 1 & 8.33 & 11 & 91.67 & \\
\hline Dianbai & 0 & 0 & 6 & 100 & \\
\hline Shantung & 0 & 0 & 9 & 100 & \\
\hline Yangjiang & 0 & 0 & 18 & 100 & \\
\hline Time of sampling & & & & & $\varangle 0.01$ \\
\hline 2019 & March & 5 & 33.33 & 10 & 66.67 \\
\hline
\end{tabular}




\begin{tabular}{llllll}
\hline April & 2 & 13.33 & 13 & 86.67 \\
\hline May & 4 & 28.57 & 10 & 71.43 \\
\hline June & 0 & 0 & 14 & 100 \\
\hline July & 0 & 0 & 17 & 100 \\
\hline August & 0 & 0 & 15 & 100 \\
\hline September & 0 & 0 & 16 & 100 \\
\hline October & 0 & 0 & 16 & 100 \\
\hline November & 1 & 0 & 16 & 94.12 \\
\hline December & 5 & 31.25 & 11 & 68.75 \\
\hline January & 5 & 31.25 & 11 & 68.75 \\
\hline February & 4 & 23.53 & 13 & 76.47
\end{tabular}

* Fisher exact test $\mathrm{p}$ value comparing detected and not detected groups

Table 4

Concentration data set of PSTs of all samples and by shellfish species, sources, time of sampling 


\begin{tabular}{|c|c|c|c|c|c|c|c|c|}
\hline & \multicolumn{2}{|c|}{$\begin{array}{l}\text { Number of } \\
\text { samples }\end{array}$} & \multicolumn{2}{|c|}{ Mean $(\mu \mathrm{g} / \mathrm{kg})$} & \multicolumn{2}{|c|}{$P_{95}(\mu \mathrm{g} / \mathrm{kg})$} & \multicolumn{2}{|c|}{$\operatorname{Max}(\mu \mathrm{g} / \mathrm{kg})$} \\
\hline & $\mathrm{n}$ & $\mathrm{n} \%$ & LB & UB & LB & UB & LB & UB \\
\hline Total species & 188 & 100 & 10.85 & 134.06 & 91.09 & 195.09 & 715.60 & 796.00 \\
\hline $\begin{array}{l}\text { Paphia } \\
\text { undulata }\end{array}$ & 40 & 21.28 & 1.29 & 125.42 & 0.99 & 124.95 & 49.81 & 172.78 \\
\hline $\begin{array}{l}\text { Chlamys } \\
\text { nobilis }\end{array}$ & 34 & 18.09 & 50.84 & 170.90 & 710.26 & 790.66 & 715.60 & 796.00 \\
\hline $\begin{array}{l}\text { Crassostrea } \\
\text { rivularis }\end{array}$ & 23 & 12.23 & 5.88 & 129.09 & 54.42 & 168.42 & 60.79 & 174.79 \\
\hline Perna viridis & 20 & 10.64 & 1.64 & 125.41 & 12.37 & 134.23 & 13.68 & 134.64 \\
\hline $\begin{array}{l}\text { Meretrix } \\
\text { meretrix }\end{array}$ & 18 & 9.57 & 0.00 & 124.16 & 0.00 & 124.16 & 0.00 & 124.16 \\
\hline $\begin{array}{l}\text { Atrina } \\
\text { pectinate }\end{array}$ & 12 & 6.38 & 0.06 & 124.20 & 0.69 & 124.65 & 0.69 & 124.65 \\
\hline $\begin{array}{l}\text { Sinonovacula } \\
\text { constricta. } \\
\text { constricta }\end{array}$ & 11 & 5.85 & 0.00 & 124.16 & 0.00 & 124.16 & 0.00 & 124.16 \\
\hline $\begin{array}{l}\text { Babylonia } \\
\text { areolate }\end{array}$ & 10 & 5.32 & 6.09 & 129.77 & 60.86 & 180.23 & 60.86 & 180.23 \\
\hline $\begin{array}{l}\text { Ruditapes } \\
\text { philippinara }\end{array}$ & 6 & 3.19 & 0.00 & 124.16 & 0.00 & 124.16 & 0.00 & 124.16 \\
\hline $\begin{array}{l}\text { Patinopecten } \\
\text { yessoensis }\end{array}$ & 5 & 2.66 & 0.00 & 124.16 & 0.00 & 124.16 & 0.00 & 124.16 \\
\hline $\begin{array}{l}\text { Scapharca } \\
\text { broughtoni }\end{array}$ & 3 & 1.60 & 0.27 & 124.36 & 0.80 & 124.74 & 0.80 & 124.76 \\
\hline Solen gouldi & 2 & 1.06 & 0.00 & 124.16 & 0.00 & 124.16 & 0.00 & 124.16 \\
\hline $\begin{array}{l}\text { Mytilus } \\
\text { edulis }\end{array}$ & 2 & 1.06 & 0.00 & 124.16 & 0.00 & 124.16 & 0.00 & 124.16 \\
\hline $\begin{array}{l}\text { Scapharca } \\
\text { subcrenata }\end{array}$ & 2 & 1.06 & 14.61 & 137.27 & 29.22 & 150.38 & 29.22 & 150.38 \\
\hline
\end{tabular}

\section{Sources}

\begin{tabular}{lllllllll} 
Huidong & 31 & 16.49 & 2.49 & 126.20 & 13.68 & 134.64 & 60.79 & 174.79 \\
\hline Zhanjiang & 31 & 16.49 & 6.24 & 129.19 & 54.42 & 168.42 & 78.02 & 181.58 \\
\hline Aotou & 21 & 11.17 & 0.24 & 124.33 & 0.55 & 124.51 & 4.54 & 127.30 \\
\hline Yangjiang & 18 & 9.57 & 0.00 & 124.16 & 0.00 & 124.16 & 0.00 & 124.16 \\
\hline Fukien & 17 & 9.04 & 0.03 & 124.18 & 0.52 & 124.48 & 0.52 & 124.48 \\
\hline Nan'ao & 17 & 9.04 & 97.12 & 214.29 & 715.60 & 796.00 & 715.60 & 796.00 \\
\hline Guangxi & 16 & 8.51 & 3.16 & 127.23 & 49.81 & 172.78 & 49.81 & 172.78
\end{tabular}




\begin{tabular}{|c|c|c|c|c|c|c|c|c|c|}
\hline & Zhuhai & 12 & 6.38 & 0.10 & 124.25 & 1.18 & 125.14 & 1.18 & 125.14 \\
\hline & Hainan & 10 & 5.32 & 6.09 & 129.77 & 60.86 & 180.23 & 60.86 & 180.23 \\
\hline & Shantung & 9 & 4.79 & 0.00 & 124.16 & 0.00 & 124.16 & 0.00 & 124.16 \\
\hline & Dianbai & 6 & 3.19 & 0.00 & 124.16 & 0.00 & 124.16 & 0.00 & 124.16 \\
\hline \multicolumn{10}{|c|}{ Time of sampling } \\
\hline \multirow[t]{10}{*}{2019} & March & 15 & 7.98 & 49.45 & 170.46 & 710.26 & 790.66 & 710.26 & 790.66 \\
\hline & April & 15 & 7.98 & 47.75 & 168.99 & 715.60 & 796.00 & 715.60 & 796.00 \\
\hline & May & 14 & 7.45 & 0.66 & 124.60 & 4.54 & 127.30 & 4.54 & 127.30 \\
\hline & June & 14 & 7.45 & 0.00 & 124.16 & 0.00 & 124.16 & 0.00 & 124.16 \\
\hline & July & 17 & 9.04 & 0.00 & 124.16 & 0.00 & 124.16 & 0.00 & 124.16 \\
\hline & August & 15 & 7.98 & 0.00 & 124.16 & 0.00 & 124.16 & 0.00 & 124.16 \\
\hline & September & 16 & 8.51 & 0.00 & 124.16 & 0.00 & 124.16 & 0.00 & 124.16 \\
\hline & October & 16 & 8.51 & 0.00 & 124.16 & 0.00 & 124.16 & 0.00 & 124.16 \\
\hline & November & 17 & 9.04 & 0.07 & 124.22 & 1.18 & 125.14 & 1.18 & 125.14 \\
\hline & December & 16 & 8.51 & 15.06 & 136.13 & 78.02 & 181.58 & 78.02 & 181.58 \\
\hline \multirow[t]{2}{*}{2020} & January & 16 & 8.51 & 14.08 & 136.49 & 137.41 & 242.98 & 137.41 & 242.98 \\
\hline & February & 17 & 9.04 & 6.19 & 129.95 & 49.81 & 172.78 & 49.81 & 172.78 \\
\hline
\end{tabular}

Table 5

Chronic PST exposure assessment using Shenzhen resident mean and $\mathrm{P}_{99}$ shellfish consumption data 
species

mean contamination data chronic exposure values $(\mu \mathrm{g} \mathrm{STX} \mathrm{eq./kg) \quad} \mathrm{( \mu g} \mathrm{STX} \mathrm{eq./kg} \mathrm{bw)}$

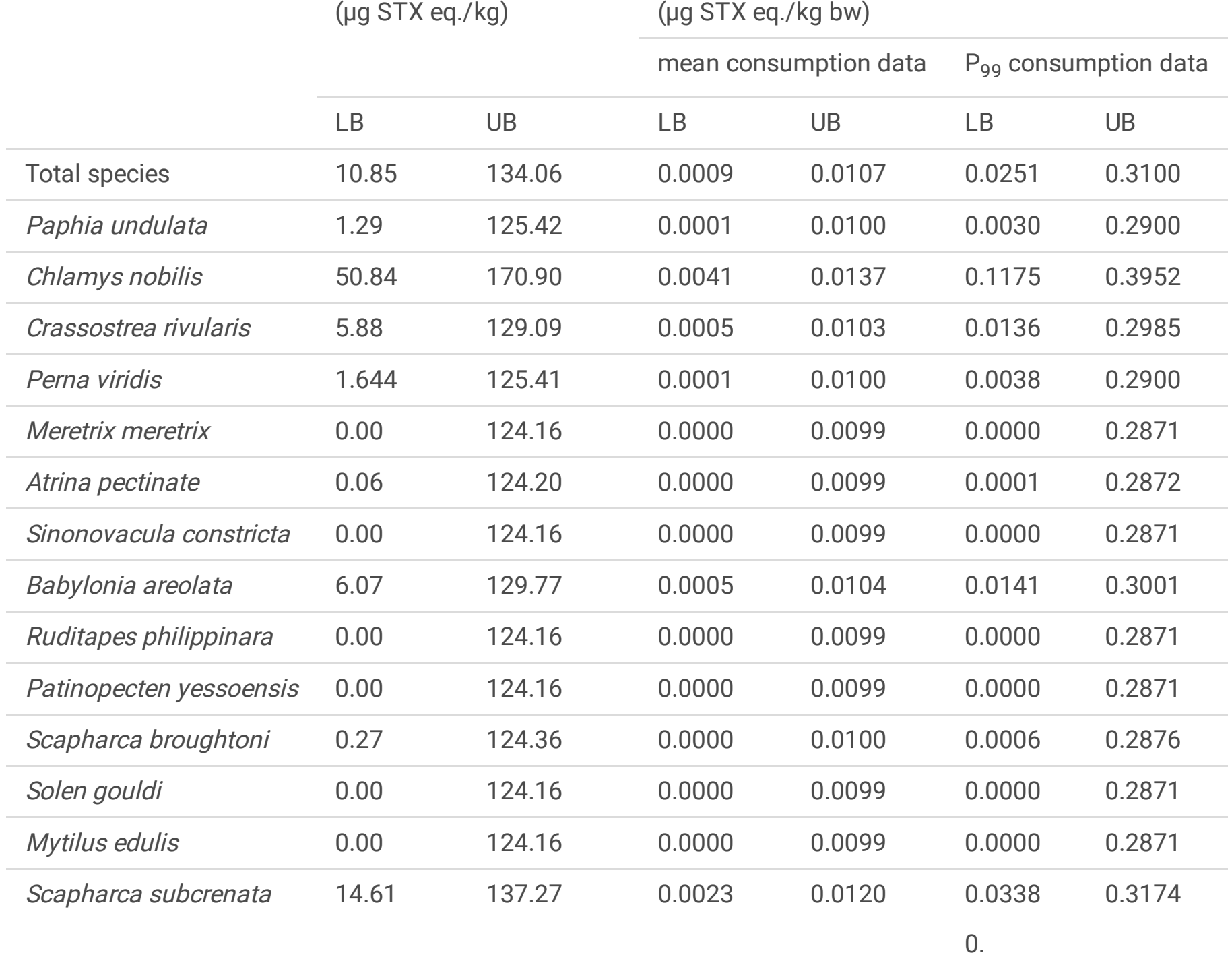

\section{Figures}




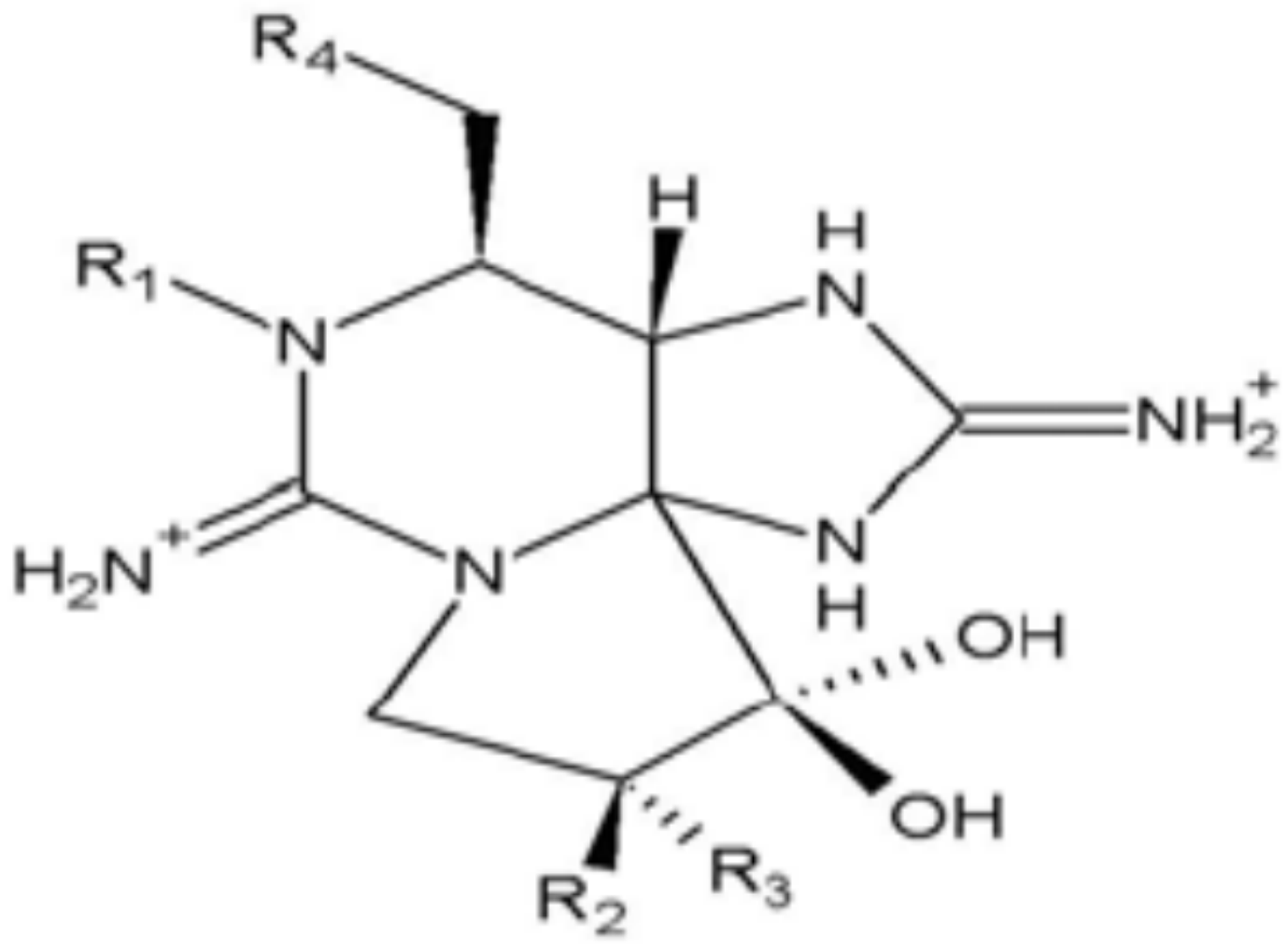

Figure 1

The chemical structure of PSTs (Wiese et al., 2010) 


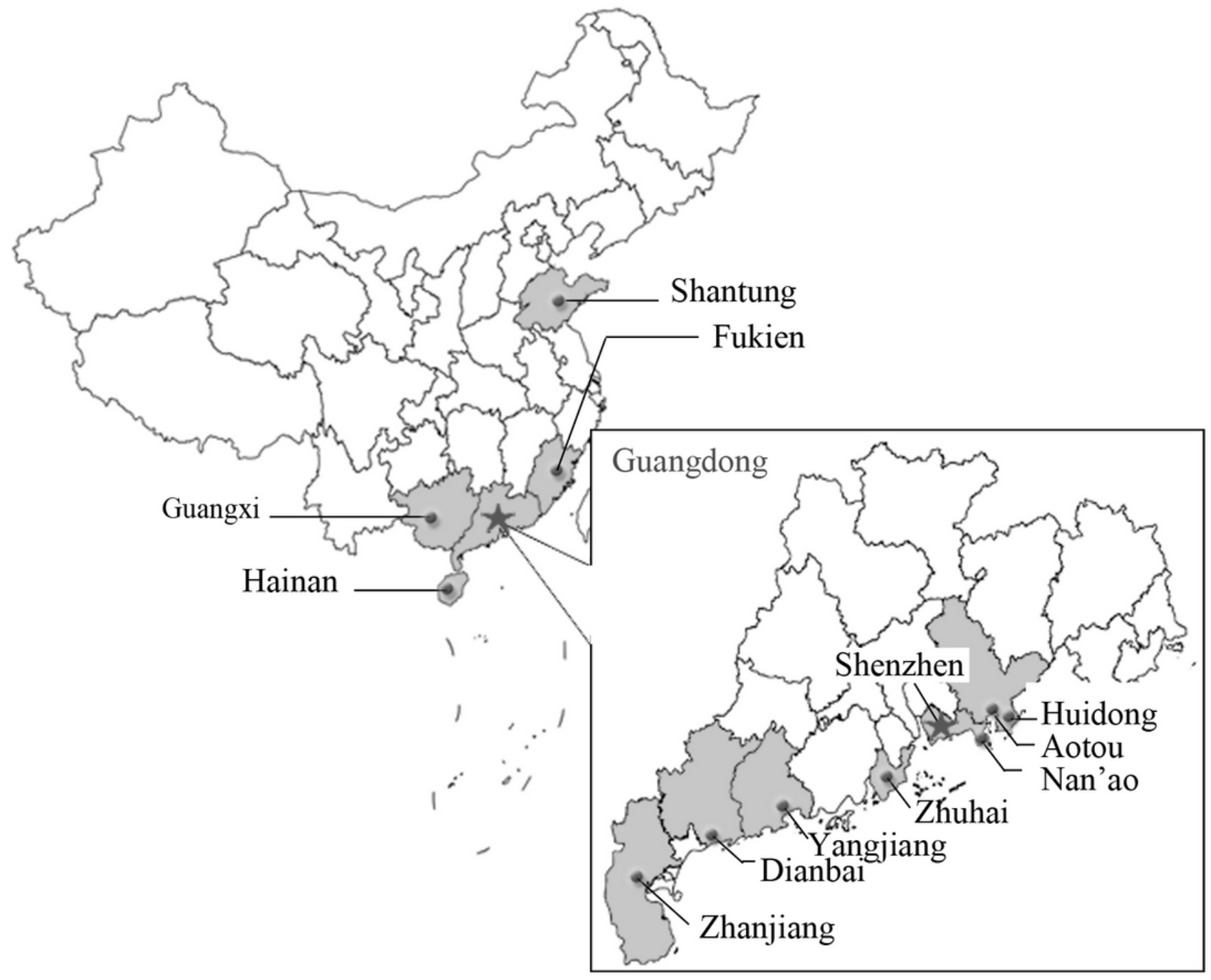

Figure 2

Locations of sample sources in China 


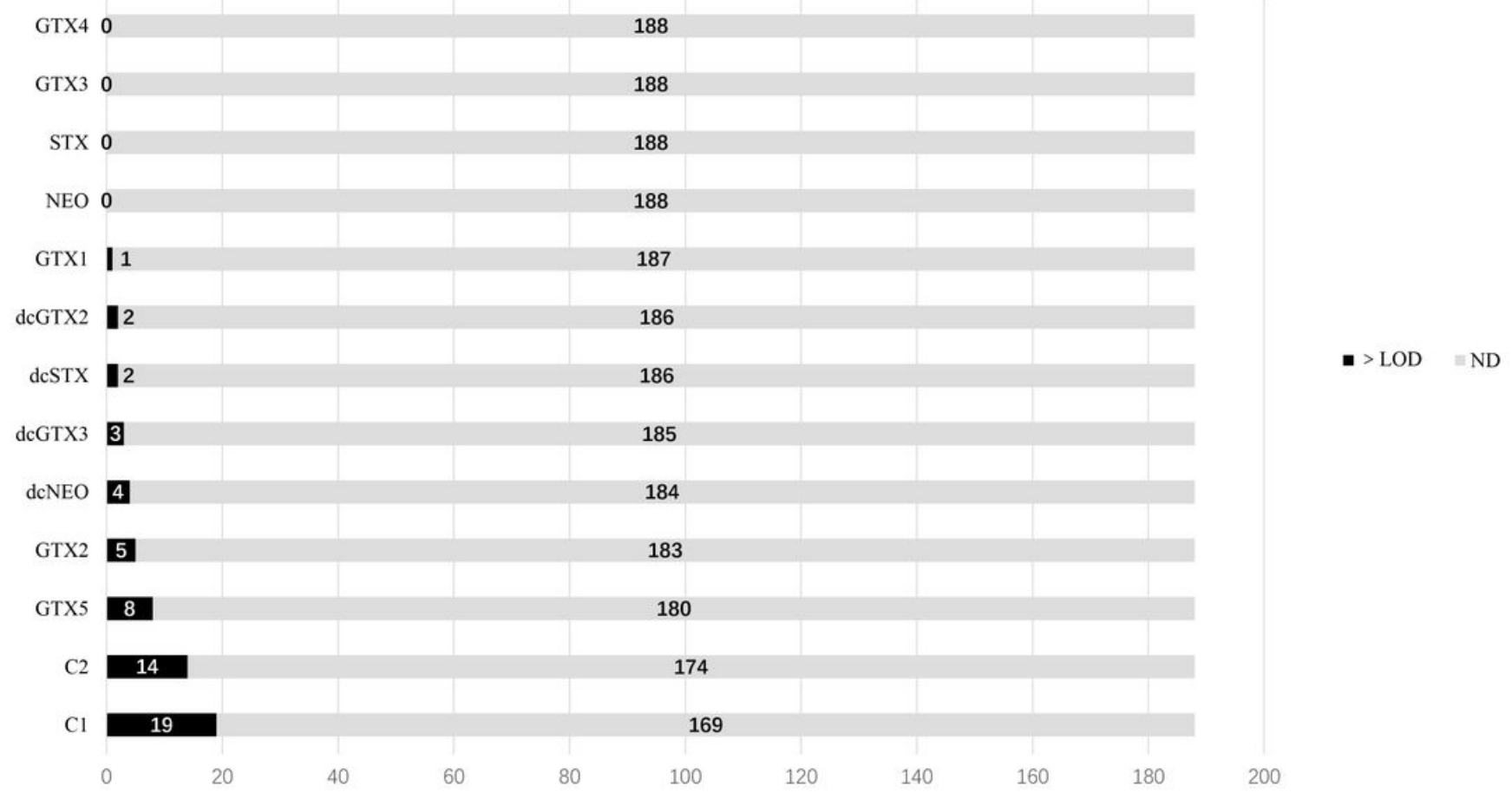

Number of samples

Figure 3

Occurrence of individual PSTs in shellfish samples

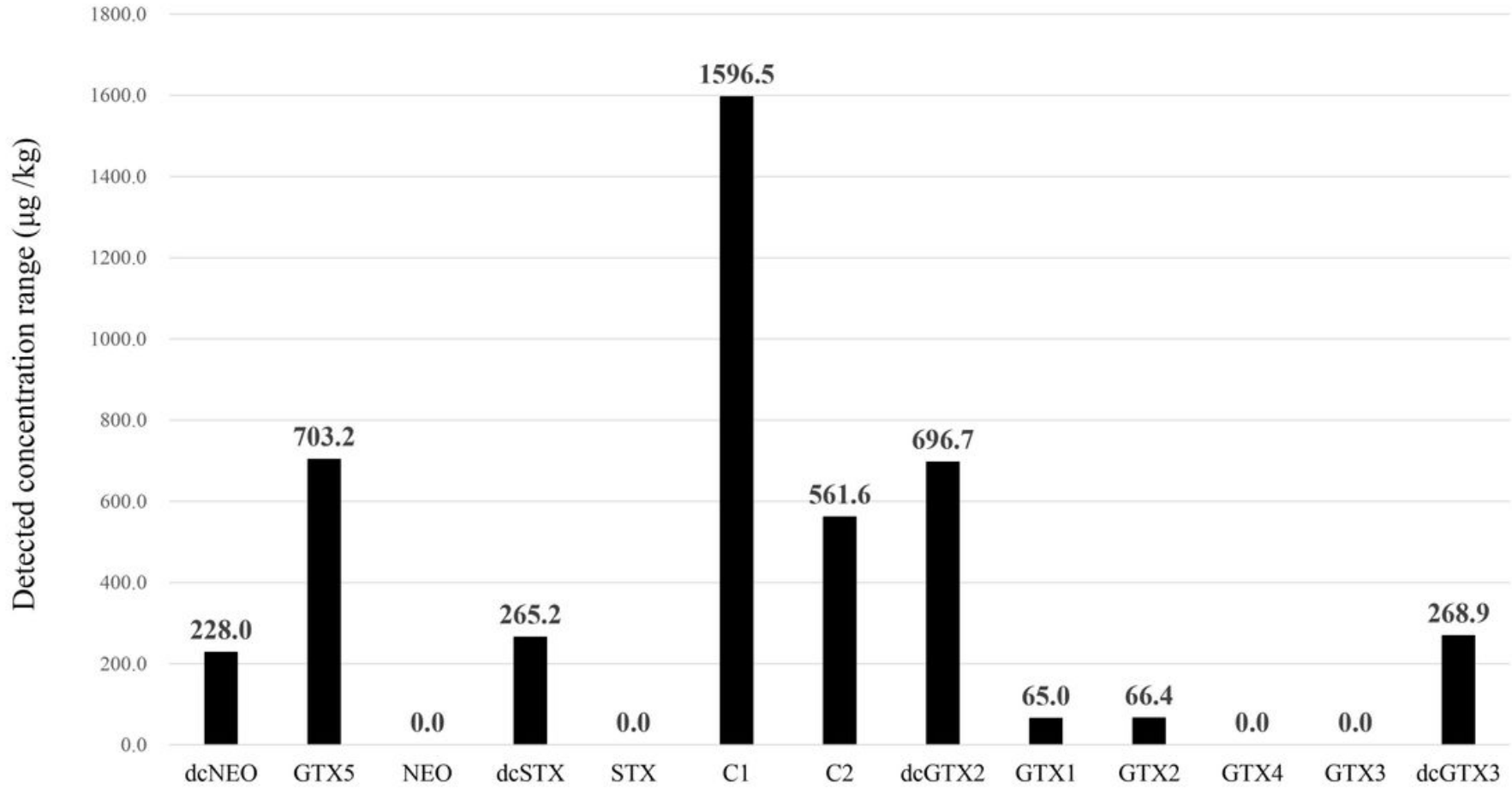

Figure 4

Detected concentration ranges of individual PST in shellfish samples

Page 21/22 


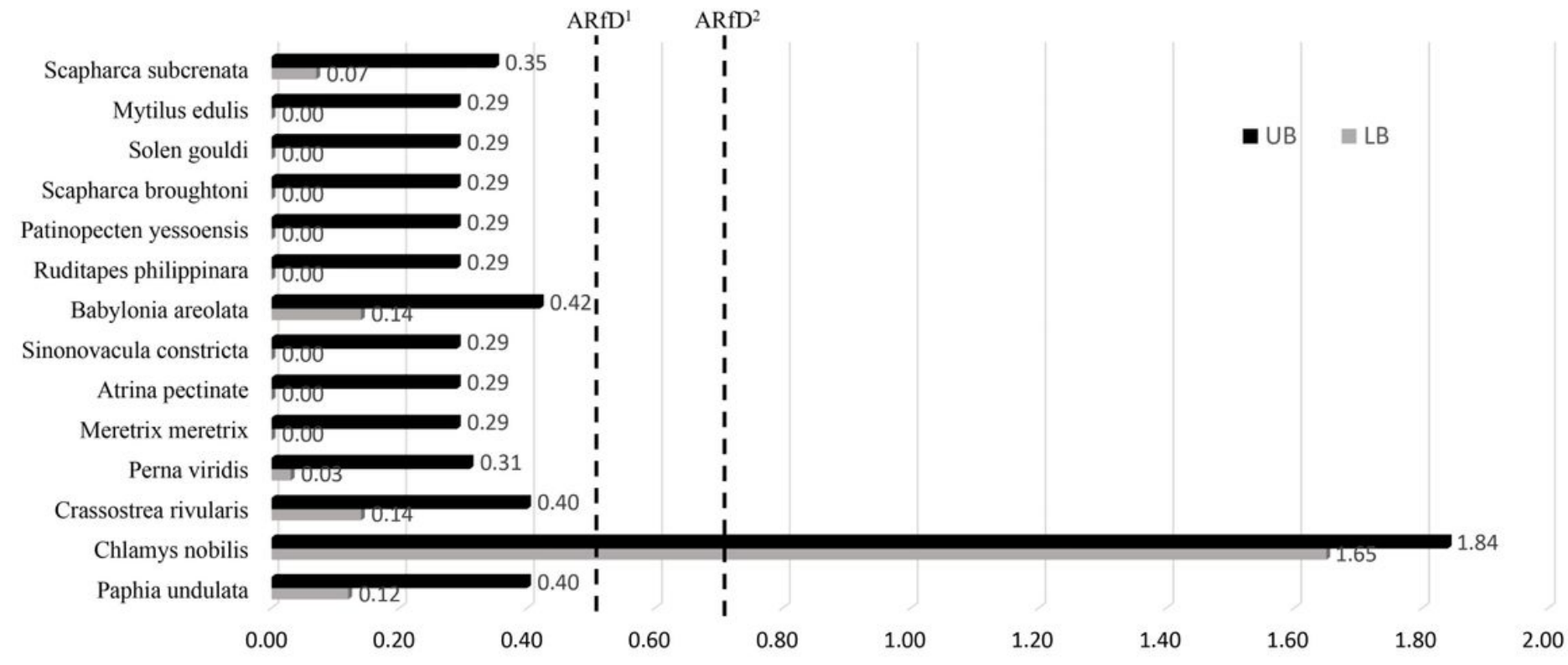

Acute dietary exposure value( $\mu \mathrm{g}$ STX eq./kg bw/day)

$\mathrm{ARfD}^{1}: 0.5 \mu \mathrm{g}$ STX eq./kg bw, recommended by EFSA;

ARfD $^{2}: 0.7 \mu \mathrm{g}$ STX eq./kg bw, recommended by FAO/IOC/WHO.

\section{Figure 5}

Acute dietary exposure values for PSTs in different shellfish species using Shenzhen resident P99 shellfish consumption data

\section{Supplementary Files}

This is a list of supplementary files associated with this preprint. Click to download.

- SupportingMaterial.docx 